\section{Brucellosis associated with deep vein thrombosis}

\author{
Ilir Tolaj, ${ }^{1}$ Murat Mehmeti, \\ Hamdi Ramadani, ${ }^{1}$ Jasmina Tolaj, ${ }^{2}$ \\ Kreshnike Dedushi, ${ }^{3}$ Hajrullah Fejza ${ }^{4}$ \\ 'Department of Infectious Diseases, \\ 2Department of Obstetrics and \\ Gynecology, ${ }^{3}$ Department of Radiology, \\ University Clinical Center of Kosovo, \\ Prishtina; ${ }^{4}$ Ministry of Health, Prishtina, \\ Kosovo
}

\section{Abstract \\ Over the past 10 years more than 700 cases of brucellosis have been reported in Kosovo, which is heavily oriented towards agriculture and animal husbandry. Here, brucellosis is still endemic and represents an uncontrolled public health problem. Human brucellosis may pres- ent with a broad spectrum of clinical manifes- tations; among them, vascular complications are uncommon. Hereby we describe the case of a 37-year-old male patient with brucellosis complicated by deep vein thrombosis on his left leg.}

\section{Introduction}

Brucellosis is a contagious zoonotic disease, which in certain conditions may be transmitted to humans through the ingestion of the agricultural products of infected animals. ${ }^{1}$ In Kosovo, a country with heavy reliance and economic orientation on agriculture and animal husbandry, human brucellosis is an endemic disease. In the past 10 years, over 700 cases of human brucellosis have been reported, with an incidence rate of 1.9 up to 4.32 per 100,000 person/year. Brucellosis causes multi-systemic diseases on humans, which can be potentially lethal due to various different clinical manifestations and complications. An uncommon complication is represented by either deep and/or superficial vein thrombosis. ${ }^{2-6}$

Hereby we describe a case of human brucellosis complicated by deep vein thrombosis and report the sequence of events leading to its diagnosis. This is the first case reported in Kosovo.

\section{Case Report}

A 37-year old male was hospitalized complaining of pain on his back, left hip and left leg; pain was further exacerbated when walking. This condition started about five months earlier, beginning initially with pain of the left talo-crural joint, eventually spreading to both legs, later with the onset of an intermittent low level fever, occasional sweats and myalgia. Before hospital admission the patient was treated symptomatically with painkillers until one month before his admission, in July 2009.

The patient and his family owned up to 500 sheep, 275 of them were proven to be infected with Brucella; 150 lambs on his farm had already died. The patient also reported that he had ingested unpasteurized sheep milk as well as cheese made from the same milk. At clinical examination upon admission the patient complained with low back pain and painful walking; left sacroiliac joint were painful on palpation. A slight hepatomegaly was evidenced. The rest of the physical examination was unremarkable. The calf circumference was identical on both legs with no signs of deep or superficial vein thrombosis or local infection present on the left leg or anywhere else.

Laboratory analysis showed the following results: erythrocyte sedimentation rate 12 $\mathrm{mm} / \mathrm{hr}$, red blood cells $5.2 \times 10^{12} / \mathrm{L}$, hemoglobin $14.3 \mathrm{~g} / \mathrm{L}$, white blood cells $12.5 \times 10^{9} / \mathrm{L}(65 \%$ neutrophils), C reactive protein $35 \mathrm{mg} / \mathrm{L}$, platelets $332 \times 10^{12} / \mathrm{L}$, hematocrit $48.7 \%$, aspartate aminotransferase $27 \mathrm{U} / \mathrm{L}$, alanine aminotranferase $25 \mathrm{U} / \mathrm{L}$. Anticardiolipin and lupus anticoagulant were negative and Protein $\mathrm{C}$, protein S, antithrombin III, and activated protein $\mathrm{C}$ resistance activity were within the normal ranges. Standard tube agglutination testing of initial samples resulted positive for antibodies to Brucella with titer 1/640.

The results of other routine biochemical blood tests were in the normal range. Chest Xray and abdominal ultrasound were normal; pelvis X-ray showed sacroileitis of the left sacroiliac joint. The computed tomography scan of lumbar/scaral part of vertebral column showed a slight medial disc L4/L5 protrusion and outpatient treatment with analgesics and anti-inflammatory non-steroids did not result in substantial improvement of his condition.

Based on the positive epidemiological survey, the patient's history of ingesting unpasteurized sheep milk and sheep cheese made from the same milk coupled together with the exhibited symptoms and clinical signs, the presence of the sacroileitis and positive Wright test, diagnosis of brucellosis was made.

The patient was initially treated with streptomycin and doxycycline for two weeks, continuing the treatment with doxycycline and rifampicin for six months. On the third week of hospitalization, the patient developed pain, edema, and redness of his left leg accompanied by fever up to $38.5^{\circ} \mathrm{C}$. Echo Doppler of lower limbs veins resulted in acute thrombosis of vena iliaca communis (VIC), vena iliaca
Correspondence: Hajrullah Fejza, Ministry of Health, Zagreb Street, Prishtina Kosovo. Tel.: +381.382 .13886 .

E-mail: drfejzah@gmail.com

Key words: brucellosis, vein thrombosis, Kosovo.

Contributions: IT, MM diagnosed the case and interpreted the results and conceived the report, KD provided ultrasound images; HR provided contact with patient; JT and HF designed and prepared the manuscript for publication.

Conflict of interests: the authors declare no potential conflict of interests.

Received for publication: 8 July 2014.

Revision received: 12 October 2014.

Accepted for publication: 12 Octobe $r 2014$.

This work is licensed under a Creative Commons Attribution NonCommercial 3.0 License (CC BYNC 3.0).

CCopyright I. Tolaj et al., 2014

Licensee PAGEPress, Italy

Infectious Disease Reports 2014; 6:5441

doi:10.4081/idr.2014.5441

externa (VIE), vena femoralis communis (VFC), vena femoralis profunda (VFP), vena femoralis superficialis (VFS), vena poplitea (VP), vena saphena magna (VSM), and vena saphena parva(VSP) of the left leg (Figure 1A).

Warfarin in accordance with the thrombotest (INR range 2.0-3.0) was added to the antibiotic treatment, and was kept for five months.

Repeated Echo Doppler of the same veins one month later resulted in some improvement, left VIC showed light re-channeling close to its wall; VIE, VFC, VFS, and VP showed signs of rechanneling (Figure 1B)

Six month after hospitalization Wright assay showed a titer of 1/80, and Echo Doppler of his left leg showed that VIC was partially rechanneled (chronic thrombosis), while VFC, VFS, VP, VSM, showed full rechanneling (Figure 1C). Patient was treated as inpatient for a period of two months and than was followed up for another 10 months. During the whole period the patient was asymptomatic.

\section{Discussion}

Complications of acute brucellosis may affect any organ system, however cardiovascular complications are very rare. Endocarditis occurs in less than $2 \%$ of the cases albeit with very high mortality rate. The aortic, mitral and prosthetic valve was reported to be affected. ${ }^{1}$ Deep vein thrombosis is a rare complication of 
acute brucellosis. ${ }^{2-6}$ Certain cases of cerebral thrombosis, ${ }^{7,8}$ benign central vein thrombosis, ${ }^{9}$ endocarditis in association with superficial femoral artery thrombus, ${ }^{10}$ thrombotic microangiopathy, ${ }^{11}$ thrombosis of abdominal aorta, ${ }^{12}$ and portal thrombosis, ${ }^{13}$ all arising from brucellosis, were occasionally reported.

In a recent review of the literature, Koubaa et al. ${ }^{14}$ described 9 reported cases of vein thrombosis associated with brucellosis, from 1973 to 2012. Ratio male female was $4 / 3$ (in 2 cases this information was lacking), age ranged from 18 to 52 years (median 41 years). Deep vein thrombosis involved legs in 5 cases, brain in 2 cases, lower limb in 1 case and portal vein in one case. ${ }^{14}$

Deep vein thrombosis of one leg is the main represented feature in the literature, including our case that developed this complication on the left leg three weeks after hospitalization.

Cem Gul et al. ${ }^{2}$ reported a similar case of a male patient of 21 years of age, who developed a deep vein thrombosis on the left leg, in which the $B$. melitensis was isolated from the blood culture thus ruling out other possible causes ofvein thrombosis. ${ }^{2}$ Ertek et al. reported that out of 216 adults with brucellosis treated in their clinic, seven of them had cardiovascular system complications, while deep vein thrombosis developed in only two of the cases. ${ }^{3}$ Further cases pertaining to deep vein thrombosis were reported by Odeh et al. (right leg, related to acute brucellosis). ${ }^{4}$ Memish et al. has also reported a case of 41 years old male patient with the venogram resulted in deep vein thrombosis of left calf. Although the blood culture was negative, the patient developed high Brucella antibody titers. ${ }^{5}$

The pathogenesis of this complication hasn't been clearly described yet. Experiments with purified antigens from the bacterial outer membrane revealed that lipoproteins (Omp 19), but not lipopolisacharide, mediate proinflamatory responses. Infection of microvascular endothelial cell line HMEC-1 cells resulted in an increased capacity of these cells to promote the transmigration of neutrophils from the apical to the basolateral side of the monolayer, and the same phenomenon was observed when the cells were stimulated with live bacteria from the basolateral side. Overall, these results suggest that Brucella spp. can infect and survive within endothelial cells, and can induce a proinflammatory response that might be involved in the vascular manifestation of brucellosis. ${ }^{6}$ Other suggested mechanisms by which brucellosis may cause deep vein thrombosis include direct endothelial damage by infection, granulomatous endophlebitis, compression from a local soft tissue mass or abscess, induction of a transient hypercoagulable state, and an immune reaction in the vessel wall to a Brucella antigen. ${ }^{14}$
A

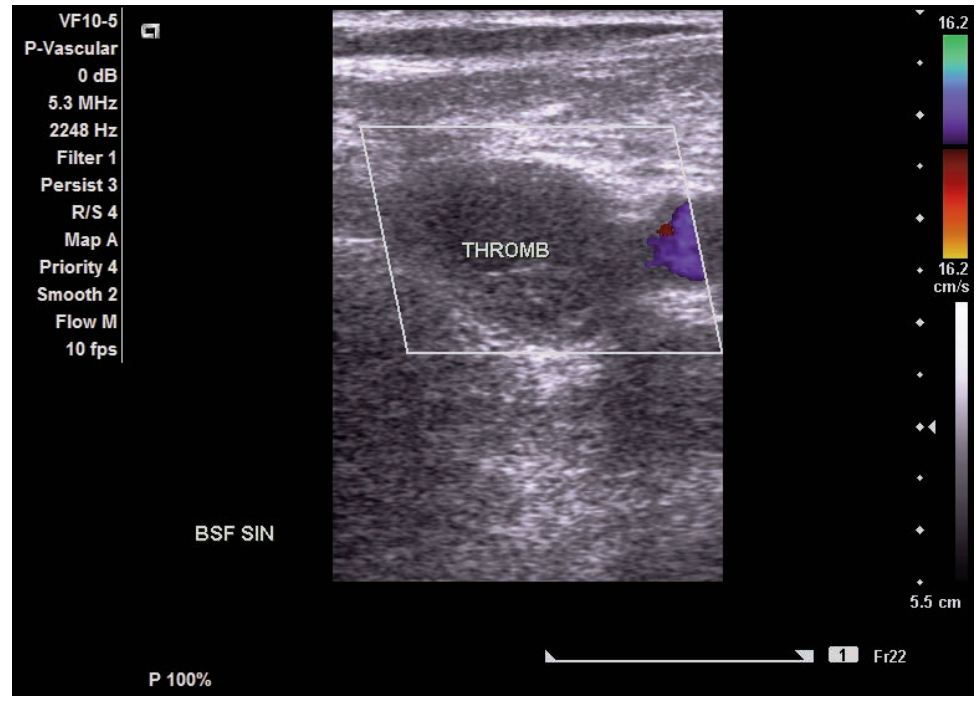

B

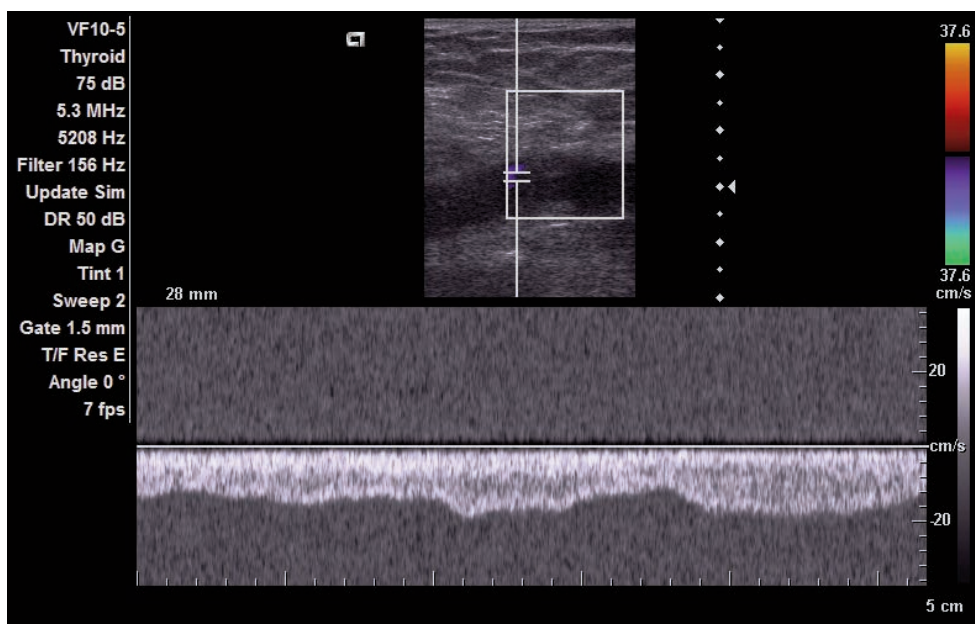

C

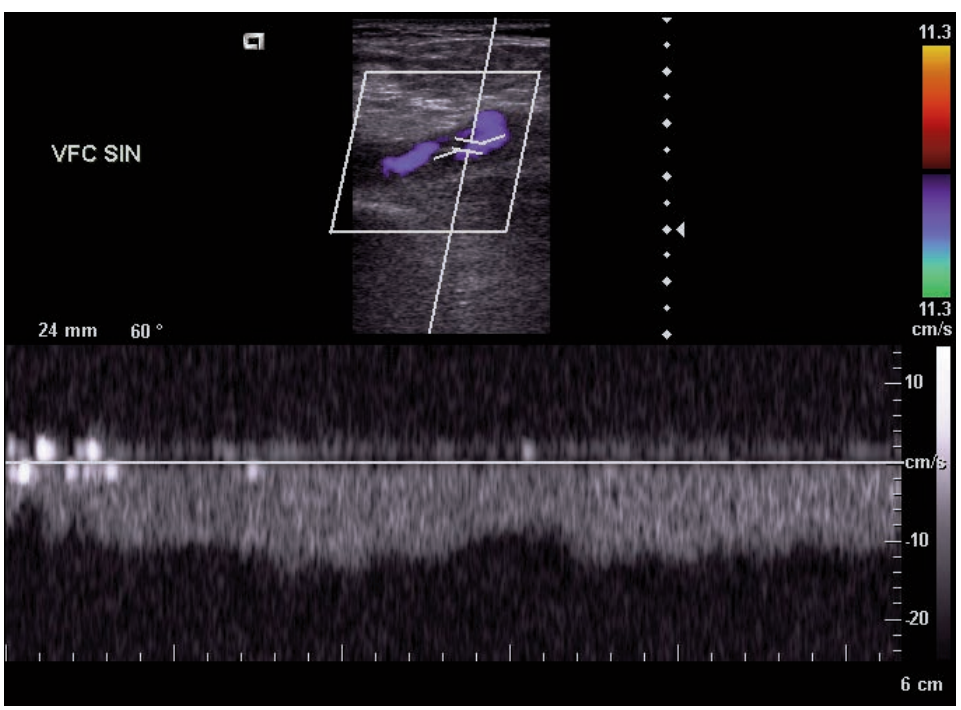

Figure 1. A) Hyper echogenic content inside the lumen of left vena femoralis communis (VFC) and vena saphena magn, during augmentation it is not compressible and there is no flux during Doppler US examination which corresponds to acute thrombosis. B) Circumscriptive hyper echogenic content on the left VFC lumen is noted, partially compressed during augmentation with presence of partial flux inside the vein lumen that correspond with thrombosis in the process of rechanneling. C) Left VFC is almost completely filled with flux, with no mural thrombi and during augmentation is completely compressed which correspond with complete rechanneling. 


\section{Conclusions}

Brucellosis should be considered as a possible etiological cause of cardiovascular system diseases, including deep vein thrombosis, particularly in patients from Brucella endemic areas. Clinicians should be aware of this possible complication, whose early diagnosis may lead to prompt and effective treatment.

\section{References}

1. Mikolich DJ, Boyce JM. Brucella species. In: Mandell GL, Bennett JE, Dolin R, eds. Principles and practice of infectious diseases. $\quad 6^{\text {th }}$ ed. London: Churchill Livingstone; 2005. pp 2670-3.

2. Cem Gul H, Mert G, Erden H, et al. Brucellosis associated with thrombophlebitis: a case report. Am J Case Rep
2008;9:31-3.

3. Ertek M, Yazgi H, Kadanali A, et al. Complications of Brucella infection among adults: an 18-year retrospective evaluation. Turk J Med Sci 2006;36:377-81.

4. Odeh M, Pick N, Oliven A. Deep venous thrombosis associated with acute brucellosis-case report. Angiology 2000;51:253-6.

5. Memish ZA, Bannatyne M, Alshahalan M. Endophlebitis of the leg caused by Brucella infection. J Infect 2001;42:281-3.

6. Ferrero MC, Bregante J, Delpino VM, et al. Proinflamatory response of human endothelial cells to Brucella infection. Microbes Infect 2011;13:852-61.

7. Lawson CW, Leeson CA. Cerebral thrombosis complicating abortus fever. Br Med J 1954;2:1400-1.

8. Zaidan R, Al Taharan AR. Cerebral venous thrombosis: a new manifestation of neurobrucelloosis. Clin Infect Dis 1999;28:399400.

9. Romem M, Singer L, Isakov J. [Bening central vein thrombosis due to brucel- losis]. Harefuah 1973;85:587-8. [Article in Hebrew].

10. Caylan R, Keske S, Durmaz T, et al. A case of Brucella endocarditis in association with superficial femoral artery thrombus. Trop Doct 2009;39:251-2.

11. Altuntas F, Eser B, Sari I, et al. Severe thrombotic microangiopathy associated with brucellosis successful treatment with plasmapheresis. Clin Appl Thromb Hemost 2005;11:105-8.

12. Sanchez-Gonzalez J, Garcia-Delange T, Martos F, Colmenero JD. Thrombosis of the abdominal aorta secondary to Brucella spondylitis. Infection 1996;24:261-2.

13. Gregori J, Ortufio J, Ruiz Rivas JL, Arenas M. [Brucellosis and portal thrombosis]. Rev Esp Enferm Dig 1990;78:187-8. [Article in Spanish].

14. Koubaa M, Frigui M, Cherif Y, et al. Deep vein thrombosis associated with acute brucellosis: a case report and review of the literature. Korean J Intern Med 2013;28: 628-30. 